J. Dairy Sci. 95:2977-2987

http://dx.doi.org/10.3168/jds.2011-4719

(C) American Dairy Science Association ${ }^{\circledR}, 2012$.

\title{
The economic effects of whole-herd versus selective anthelmintic treatment strategies in dairy cows
}

\author{
J. Charlier, ${ }^{\star 1}$ B. Levecke, ${ }^{\star}$ B. Devleesschauwer, ${ }^{\star} \dagger$ J. Vercruysse, ${ }^{\star}$ and H. Hogeveen $¥ \S$ \\ *Department of Virology, Parasitology and Immunology, Salisburylaan 133, 9820 Merelbeke, Ghent University, Belgium \\ †Institute of Health and Society, Catholic University of Louvain, Clos Chapelle-aux-Champs 30, 1200 Brussels, Belgium \\ łBusiness Economics, Wageningen University, PO Box 8130, 6706 KN Wageningen, the Netherlands \\ $\S$ Department of Farm Animal Health, Faculty of Veterinary Medicine, Utrecht University, PO Box 80151, 3508 TD, the Netherlands
}

\begin{abstract}
Current control practices against gastrointestinal nematodes in dairy cows rely strongly on anthelmintic use. To reduce the development of anthelmintic resistance or disposition of drug residues in the environment, novel control approaches are currently proposed that target anthelmintic treatment to individual animals instead of the whole herd. However, such selective treatment strategies come with additional costs for labor and diagnostics and, so far, no studies have addressed whether they could be economically sustainable. The objectives of this study were to (1) investigate the economic effects at farm level of whole-herd versus more selective anthelmintic treatment strategies in adult dairy cows, and (2) determine how these economic effects depend on level of infection and herd size. A Monte Carlo simulation, fed by current epidemiological and economical knowledge, was used to estimate the expected economic effects and possible variation of different control strategies under Belgian conditions. Four treatment strategies were compared with a baseline situation in which no treatments were applied: whole herd at calving (S1), selective at calving with (S2) or without (S3) treatment of the first-calf cows, and wholeherd when animals are moved from grazing to the barn in the fall (housing treatment, S4). The benefit per lactation for an average dairy herd varied between $-\$ 2$ and $\$ 131$ (average $\$ 64$ ) for S1, between $-\$ 2$ and $\$ 127$ (average $\$ 62$ ) for $\mathrm{S} 2$, between $-\$ 17$ and $\$ 104$ (average $\$ 43)$ for $\mathrm{S3}$, and between $-\$ 41$ and $\$ 72$ (average $\$ 15$ ) for S4. The farmer's risk associated with any treatment strategy, as indicated by the width of the $95 \%$ credible intervals of economic benefit of anthelmintic treatment, decreased with increasing level of exposure, as assessed by bulk tank milk ELISA. The order of the different strategies when sorted by expected benefit was robust
\end{abstract}

Received July 12, 2011.

Accepted January 27, 2012.

${ }^{1}$ Corresponding author: johannes.charlier@ugent.be to changes in economic input parameters. We conclude that, on average, strategies applying anthelmintic treatment at calving outperform a strategy applying treatment at housing. Within the strategies that applied treatment at calving, more selective treatment strategies can be economically sustainable. However, given the large variation in possible benefits within each treatment strategy, decision support systems are needed to account for the multitude of cow, epidemiological, and economic factors that determine the economics of nematode control and select the optimal treatment strategy for a specific farm.

Key words: dairy, nematode, anthelmintic, economic

\section{INTRODUCTION}

Worldwide, gastrointestinal (GI) nematode infections continue to be an important cause of production losses in pasture-based cattle production. In the temperate climate regions of the northern hemisphere, Ostertagia ostertagi and Cooperia oncophora are considered the most important species. In adult dairy cattle, the induced production losses are mainly caused by lowered milk yield and fertility (Gross et al., 1999; Sanchez et al., 2002b, 2004; Charlier et al., 2009a).

The use of anthelmintics, combined with pasture management practices, is the cornerstone of current control practices against GI nematodes (Bennema et al., 2010). The current anthelmintic treatment decisions taken by dairy producers are driven mainly by factors such as milk price or perceived production level of the animals, but the exact economic benefit remains unclear. This may, in large part, be attributed to the fact that veterinary science has focused mainly on controlling levels of infection without considering the economic aspects involved (Charlier et al., 2009a). The principal diagnostic used to evaluate the levels of infection and estimate the induced production losses is an O. ostertagi antibody ELISA (Boehringer Ingelheim Svanova, Uppsala, Sweden) applied to milk samples (Guitián et al., 1999; Charlier et al., 2009b). 
Besides the economic effects of GI nematode infections, societal pressure for judicious use of medicines is increasing in Europe and other parts of the world. This trend has mainly arisen in regard to antibiotic use, where intensive antibiotic use in animals is considered to enhance the emergence of antibiotic resistant zoonotic bacterial agents (Love et al., 2011). Although the principal nematode infections of cattle are not zoonotic, intensive use of anthelmintics is also considered as a problem because it selects for anthelmintic-resistant nematodes and can leave unwanted residues in the environment and food products for human consumption, threatening the sustainability of current production methods (Lumaret and Errouissi, 2002; Sutherland and Leathwick, 2011). Selective use of anthelmintics by targeting individual animals within a herd is currently promoted as an alternative for whole-herd anthelmintic treatment strategies to reduce the above-mentioned undesired side effects (Kenyon et al., 2009). However, such selective treatment strategies are currently not regularly applied because they incur additional costs for labor and diagnostics. So far, no studies have addressed whether selective treatment strategies could be economically sustainable.

The objectives of this study were (1) to investigate the economic effects at the farm level of whole-herd versus selective anthelmintic treatment strategies in adult dairy cows under Belgian conditions, and (2) to determine how these economic effects depend on level of infection and herd size. Because the process of nematode control on a dairy farm includes different epidemiological and economic aspects, with each aspect implying variation, a Monte Carlo simulation fed by current epidemiological and economic knowledge was considered the optimal way to estimate the expected economic effects and variation of different control strategies and to identify important knowledge gaps that limit the current predictions.

\section{MATERIALS AND METHODS}

\section{Model Description}

First, we will provide a general description of the model, followed by the specific characteristics. Monte Carlo simulation is a computer technique that simulates a system in which the value of variables within the system is based on repeated samples ("iterations") drawn from specified probability distributions. The used probability distributions ideally resemble the naturally occurring variation that exists in the system. The model used in this study is graphically presented in Figure 1 and consists of 3 consecutive steps: (1) simulating the

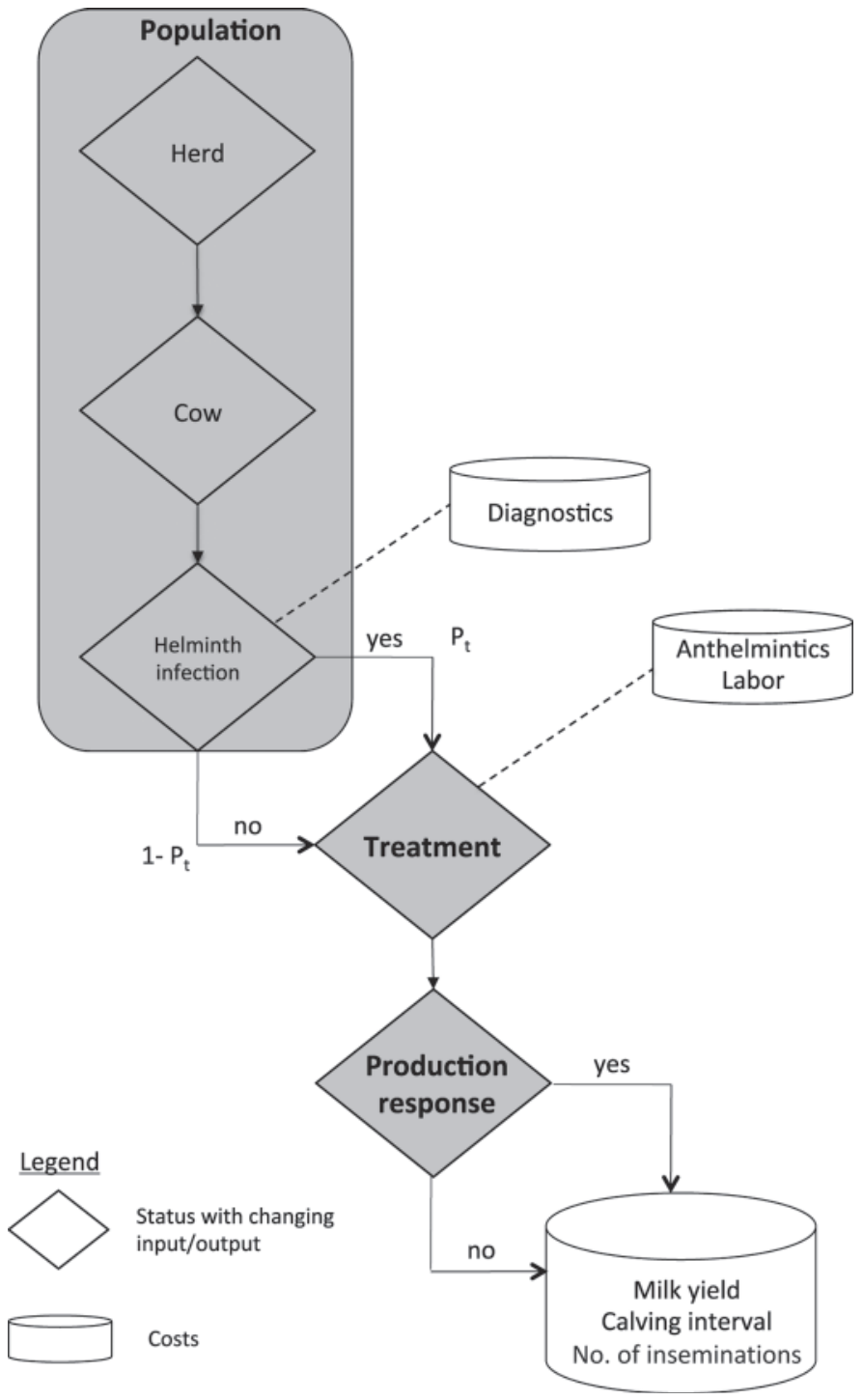

Figure 1. Schematic view of the simulation model, where $\mathrm{P}_{t}=$ probability that cow receives anthelmintic treatment.

population, (2) describing different treatment strategies and their effect on production parameters, and (3) assessing the costs or revenues of these strategies.

The population is characterized by a herd size and level of infection with GI nematodes. The level of infection with GI nematodes on the herd or individual level is determined by an ELISA applied on bulk tank milk or individual milk samples, respectively. The test results of this ELISA are expressed as an optical density ratio (ODR). The probability that a cow receives anthelmintic treatment $\left(\mathrm{P}_{\mathrm{t}}\right)$ depends on the applied strategy (see evaluated strategies). The production responses after anthelmintic treatment were a function of the individual ODR and involved effects of treatment 
on milk production and probability of conception. The number of inseminations required to conceive and the calving interval were modeled as the result of the probability of insemination given estrus and the probability of conception. Economic values were attributed to the different inputs (i.e., anthelmintics, labor, and ELISA) and outputs (i.e., extra milk produced, insemination, prolongation of the calving interval) of the model. We did not include an effect of fertility on the probability of a cow being culled, as culling costs were already included in the estimates of a prolonged calving interval (Inchaisri et al., 2010). The outcome of the model was the economic benefit $(\$)$ of a certain treatment strategy compared with a baseline situation in which no control efforts were undertaken. The number of iterations per evaluated strategy was set at 10,000, the number where the difference in the expected economic effect was less than or equal to $\$ 1.5$ per cow in 3 independent simulation runs. The expected economic benefit represents the average of the 10,000 iterations for a given treatment strategy, whereas the variation (also referred to as "risk") is represented by the 5th and 95th percentile (95\% credible interval) of the iterations. The model used the euro as monetary unit, but all monetary values were converted to US dollars at a conversion rate of $€ 1=\$ 1.2669(\mathrm{US} \$ / €$ conversion rate $=0.7893)$ in this publication. The model was built in the $\mathrm{R}$ language $(\mathrm{R}$ Development Core Team, 2010) and the code is given in the supplementary file available online (http://www. journalofdairyscience.org/).

\section{Evaluated Strategies}

Five treatment strategies $(\mathbf{S})$ were simulated: $\mathrm{S} 0=$ no treatments were performed; $\mathrm{S} 1=$ all cows were treated at calving without prior diagnosis; $\mathrm{S} 2=$ all first-parity cows were treated at calving, and second or higher parity cows were treated at calving if individual ODR $\geq 0.5$; S3 = first parity cows were left untreated, and second or higher parity cows were treated at calving if individual ODR $\geq 0.5$; and $\mathrm{S} 4=$ all cows were treated at housing in the fall without prior diagnosis.

Under European conditions, cows are kept indoors during the fall and winter when grass growth has stopped. Two different timings of treatment are commonly used: (1) treatment at housing, when the cows are moved from grazing to the barn at fall, removing worm burdens for a prolonged period as no reinfection takes place during the winter period (Charlier et al., 2007b), or (2) treatment at calving, to support the cow in the beginning of lactation and to increase peak production and the subsequent lactation curve (Nødtvedt et al., 2002). In the strategy to evaluate anthelmintic treatment strategies at calving, the decision parameter needs to be available from before parturition. Because individual diagnostic test results from milk samples are not available for first-parity cows, the strategy in which cows are treated selectively was split into 2 strategies in which all first-parity cows were given anthelmintic treatment (S2) or not (S3). The outcome of strategies $\mathrm{S} 1$ to $\mathrm{S} 4$ was compared with the baseline situation in which no anthelmintic treatment was applied (S0). An outcome, further defined as "benefit" below 0 would indicate that S0 is most profitable.

\section{Input Data}

Herd and cow parameters representative of dairy herds in Flanders (Belgium) were chosen and are presented in Table 1. The herd level of infection, as measured by an $O$. ostertagi bulk tank milk ELISA, was chosen to be the average level of infection observed in a randomized cross-sectional survey in the Flemish (Belgium) dairy population (Bennema et al., 2009). A standard deviation of 0.1 ODR was applied to account for the variation that occurs in test results when the same sample is tested repeatedly (Charlier et al., 2005b, 2009b). The individual cow ODR depended on the bulk tank ODR as described in Table 1. This relationship has been described previously (Charlier et al., 2007a, 2010), is based on observations from 14 dairy herds, and assumes a Gaussian distribution of individual ODR within a herd. A mixed gamma distribution was used to represent DIM at housing, because this distribution gave the best fit to the data of 14 Flemish dairy herds in a previous study (Charlier et al., 2010). According this distribution, the proportion of cows calving in the months January-March, April-June, July-September, and October-December was 21, 16, 39, and 24\%, respectively.

Production responses after anthelmintic treatment were modeled as a relationship of the individual cow ODR as follows. A milk yield response occurs when the individual ODR $\geq 0.5$. This response was set at $2 \pm 1$ $\mathrm{kg}$ per day (mean $\pm \mathrm{SD}$ ) with a negative correction for DIM of $-0.0054 \mathrm{~kg} / \mathrm{d}$ (Nødtvedt et al., 2002; Reist et al., 2002, 2011; Sanchez et al., 2002a, 2005; Forbes et al., 2004; Gibb et al., 2005; Charlier et al., 2007b, 2010). When the treatment was applied at calving, the duration of the milk yield response was set at 6 mo (Nødtvedt et al., 2002); when the treatment was applied at housing, the duration of the milk yield response was set at the number of days until the end of lactation, with a maximum duration of 6 mo. A fixed length of lactation was used, chosen to be the average of $365 \mathrm{~d}$ in the Flemish (Belgium) dairy population (CRV, 2010). 


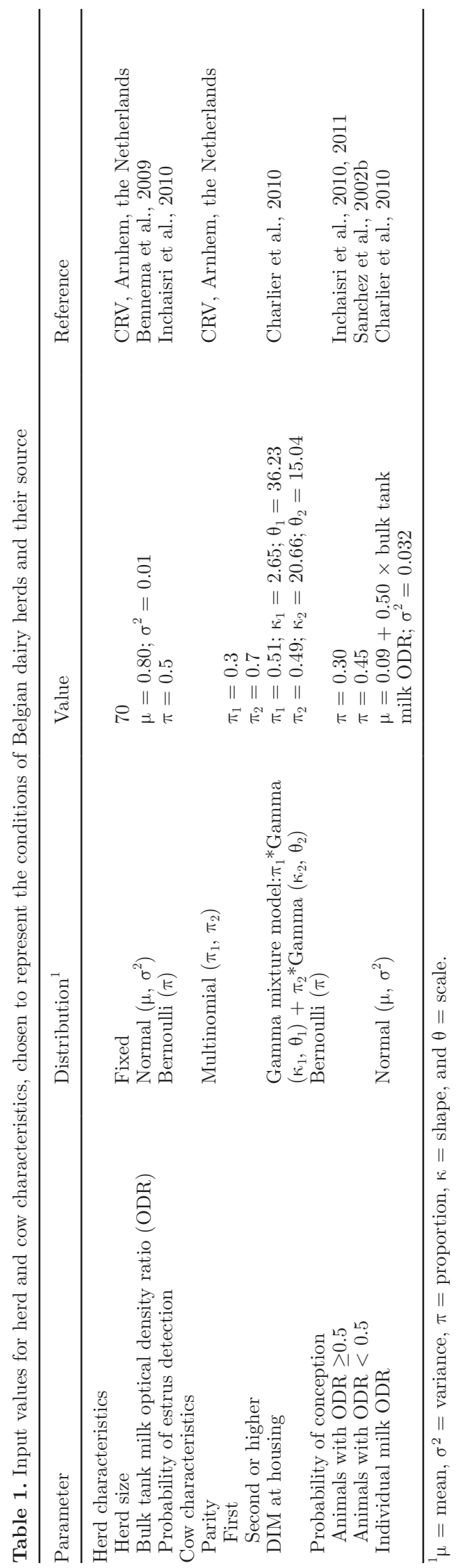

A carry-over effect of the production response of cows treated in late lactation to the subsequent lactation was evaluated, but not included in the model as the economic effect was small $(<\$ 1.5 / \mathrm{cow})$.

A treatment response on the probability of conception occurred only when the individual ODR $\geq 0.5$ and the treatment was administered at calving or within the first $75 \mathrm{~d}$ of the lactation, the assumed voluntary waiting period before the first insemination. The response was set at a recovery of the probability of conception from 0.30 to 0.45 .. These values were chosen based on Inchaisri et al. $(2010,2011)$ for the baseline probability of conception and Sanchez et al. (2002b) for the effects of anthelmintic treatment. Cows that did not conceive $253 \mathrm{~d}$ after calving were assigned a calving interval of 538 d. As explained above, costs of culling due to infertility were not considered separately, but were included in the estimated costs for a prolonged calving interval. The effect of treatment on number of inseminations per conception and the calving interval was calculated as a direct consequence of the probability of conception.

The time spent by the farmer to implement the treatment strategies was calculated as follows. For individual treatments at calving ( $\mathrm{S} 1$ to $\mathrm{S} 3$ ), the time spent to treat an animal was set at $120 \mathrm{~s}$ for preparation and $60 \mathrm{~s}$ for treatment of the animal (i.e., 3 min per animal). For whole-herd treatment at housing (S4), the time spent was set at $120 \mathrm{~s}$ for preparation and $15 \mathrm{~s}$ per animal treated. These values were chosen based on Webster et al. (2008) and an interview of 6 farmers who were involved in a clinical trial on selective anthelmintic treatments of dairy cows.

Finally, the economic input parameters of the model are presented in Table 2. The milk price of $\$ 0.27 / \mathrm{kg}$ was obtained by correcting an average milk price of $\$ 0.38$ for the cost of $0.5 \mathrm{~kg}$ of concentrate $(\$ 0.11)$ per extra kilogram of milk produced after anthelmintic treatment. This represents a non-quota situation. The European Union quota regulations will be abandoned in 2015, and farmers are currently adapting their management strategies toward a non-quota situation. The costs for prolongation of the calving interval were set at $\$ 1.18, \$ 1.27, \$ 1.34, \$ 1.41, \$ 1.47, \$ 1.51, \$ 1.55, \$ 1.58$, and $\$ 1.61$ per day for calving intervals of 370,391 , $412,433,454,475,496,517$, and 538 d, respectively (based on a decision support tool to calculate herd losses due to an extended calving interval of Wageningen University; http://www.bec.wur.nl/UK/Research/ Decision+Support+Tools).

\section{Low Impact Scenario}

The input data used above to describe production responses after treatment were based on peer-reviewed 
Table 2. Input values for economic parameters, with their source

\begin{tabular}{lcl}
\hline & $\begin{array}{c}\text { Attributed } \\
\text { cost }\left(\$^{1}\right)\end{array}$ & Source \\
\hline Milk (per kg) & 0.27 & H. Hogeveen (unpublished data) \\
Insemination & 19 & CRV, 2011 \\
Prolonged calving interval (per d) & 1.18 to 1.61 & Decision tool, Wageningen University (see text) \\
Labor (per h) & 19 & T. Meyns, Merial Belgium, personal communication \\
Anthelmintic dose of a cow & 12.67 & DGZ Vlaanderen, Torhout, Belgium \\
ELISA of a milk sample & 8.87 &
\end{tabular}

${ }^{1}$ Conversion rate: $\mathrm{US} \$ 1=€ 0.7893$ at time of study.

clinical trials conducted mainly in Europe. However, situations may exist where these responses cannot be achieved. Therefore, a low impact scenario was simulated in which the milk yield response after anthelmintic treatment was set at $0.75 \pm 0.38 \mathrm{~kg}$ (mean $\pm \mathrm{SD}$ ) per day, with a negative correction for DIM of $-0.0021 \mathrm{~kg} / \mathrm{d}$ and where no effect on probability of conception occurred, while all other parameters in the model remained the same. This scenario is based on the results of a clinical trial in New Zealand (McPherson et al., 2001) and a recently conducted trial in Canada (Vanderstichel, 2011).

\section{Effects of Herd Size and Level of Infection}

Because the treatment effects are considered to vary due to biological variation at the cow level, herd size can affect the variation (standard error) of the herd mean economic benefit of anthelmintic treatment. Therefore, the effect of herd size on the economic benefit was evaluated for herd sizes of 30 and 150, reflecting small and large herds, respectively. The effect of level of infection on the model outcome was evaluated for bulk tank ELISA results ranging from 0.2 to 1.5 ODR, reflecting the possible range of values encountered in northwestern Europe (Bennema et al., 2010). Bulk tank values of $0.2,0.8$, and 1.5 ODR correspond to a situation in which, on average, 4,48 , and $97 \%$ of individual ELISA results had ODR $\geq 0.5$, respectively.

\section{Sensitivity Analysis}

Univariate sensitivity analysis was conducted by evaluating the changes in the expected outcome following a modification in a single parameter of the input data: all economic parameters with values $-20 \%$ and $+20 \%$ of the default value were tested. We assessed both quantitative changes in the expected economic benefit as changes in the order of the treatment strategies when they were ordered from highest to lowest expected economic benefit.

\section{RESULTS}

\section{Expected Benefit of Different Treatment Strategies}

The expected benefits and variation associated with the 4 treatment strategies under Belgian conditions are shown in Table 3. The expected benefit per lactation ranged from $\$ 15$ for $\mathrm{S} 4$ to $\$ 64$ for $\mathrm{S} 1$. The expected benefits for S2 and S3 were intermediate, at $\$ 62$ and $\$ 43$, respectively. We observed wide variation in possible benefits for each treatment strategy, as indicated by the wide $95 \%$ credible intervals. The lower limit of the $95 \%$ credible intervals was below $\$ 0$ for each treatment strategy. In general, the risk to have no economic benefit after anthelmintic treatment was greater for $\mathrm{S} 3$ and S4 compared with S1 and S2.

Overall, the net benefits from extra milk yield were the largest component $(65 \%)$ in the total benefit resulting from anthelmintic treatment. Benefit from improved fertility contributed, on average, $35 \%$ to the total benefit after applying an anthelmintic treatment strategy. The cost of anthelmintics (range $\$ 4$ to $\$ 13 /$ lactation) was the greatest component in the total investment in an anthelmintic treatment strategy, followed by ELISA (range $\$ 0$ to $\$ 6 /$ lactation) and labor (range $\$ 0.09$ to $\$ 0.95 /$ lactation).

\section{Effect of Low Impact Scenario}

Applying a low impact scenario, the expected benefits (95\% credible intervals) per lactation in the standard situation were $\$ 4.28(-4.66,13.66), \$ 2.94(-4.04$, $10.24), \$ 1.65(-2.89,6.69)$, and $-\$ 5.05(-9.49,0.15)$ for S1, S2, S3, and S4, respectively.

\section{Effect of Herd Size and Level of Infection}

The effects of changes in herd size on the model outcome are shown in Figure 2. As indicated by the narrowing $95 \%$ credible intervals, the farmer's risk associated with any treatment strategy decreased with increasing herd size. 
Table 3. Proportion (\%) of animals receiving anthelmintic treatment and expected benefits (5th and 95th percentile in parentheses) of 4 anthelmintic treatment strategies (S1 to S4) in dairy herds with a herd size of 70 dairy cows under Belgian conditions (standard impact scenario) ${ }^{1}$

\begin{tabular}{|c|c|c|c|c|}
\hline \multirow[b]{2}{*}{ Component } & \multicolumn{4}{|c|}{ Treatment strategy ${ }^{2}$} \\
\hline & S1 & S2 & S3 & S4 \\
\hline Milk yield & $\begin{array}{l}47.72 \\
(23.53,72.90)\end{array}$ & $\begin{array}{l}47.74 \\
(23.54,73.00)\end{array}$ & $\begin{array}{l}33.34 \\
(14.92,53.54)\end{array}$ & $\begin{array}{l}20.71 \\
(8.67,34.42)\end{array}$ \\
\hline Calving interval & $\begin{aligned} & 19.10 \\
&(-15.90,54.98)\end{aligned}$ & $\begin{aligned} & 18.95 \\
&(-16.79,54.63)\end{aligned}$ & $\begin{aligned} & 13.09 \\
&(-21.88,48.40)\end{aligned}$ & $\begin{array}{l}4.40 \\
(-30.30,39.39)\end{array}$ \\
\hline Anthelmintics & $\begin{array}{l}-12.67 \\
(-12.67,-12.67)\end{array}$ & $\begin{array}{l}-8.15 \\
(-10.31,-5.79)\end{array}$ & $\begin{array}{l}-4.35 \\
(-6.70,-1.99)\end{array}$ & $\begin{array}{l}-12.67 \\
(-12.67,-12.67)\end{array}$ \\
\hline ELISA & $\begin{array}{l}0.00 \\
(0.00,0.00)\end{array}$ & $\begin{array}{l}-6.21 \\
(-7.09,-5.19)\end{array}$ & $\begin{array}{l}-6.21 \\
(-7.09,-5.19)\end{array}$ & $\begin{array}{l}0.00 \\
(0.00,0.00)\end{array}$ \\
\hline Labor & $\begin{array}{l}-0.95 \\
(-0.95,-0.95)\end{array}$ & $\begin{array}{l}-0.61 \\
(-0.77,-0.43)\end{array}$ & $\begin{array}{l}-0.33 \\
(-0.51,-0.15)\end{array}$ & $\begin{array}{l}-0.09 \\
(-0.09,-0.09)\end{array}$ \\
\hline
\end{tabular}

${ }^{1}$ All benefits are expressed in $\$$ per lactation. Conversion rate: US $\$ 1=€ 0.7893$ at time of study.

${ }^{2}$ Treatment strategies: $\mathrm{S} 1$ = all cows are treated at calving without prior diagnosis; $\mathrm{S} 2=$ first-parity cows are all treated at calving, and second or higher parity cows are treated at calving if individual optical density ratio (ODR) $\geq 0.5$; S3 = first-parity cows are left untreated, and second or higher parity cows are treated at calving if individual ODR $\geq 0.5 ; \mathrm{S} 4=$ all cows are treated at housing in fall without prior diagnosis.

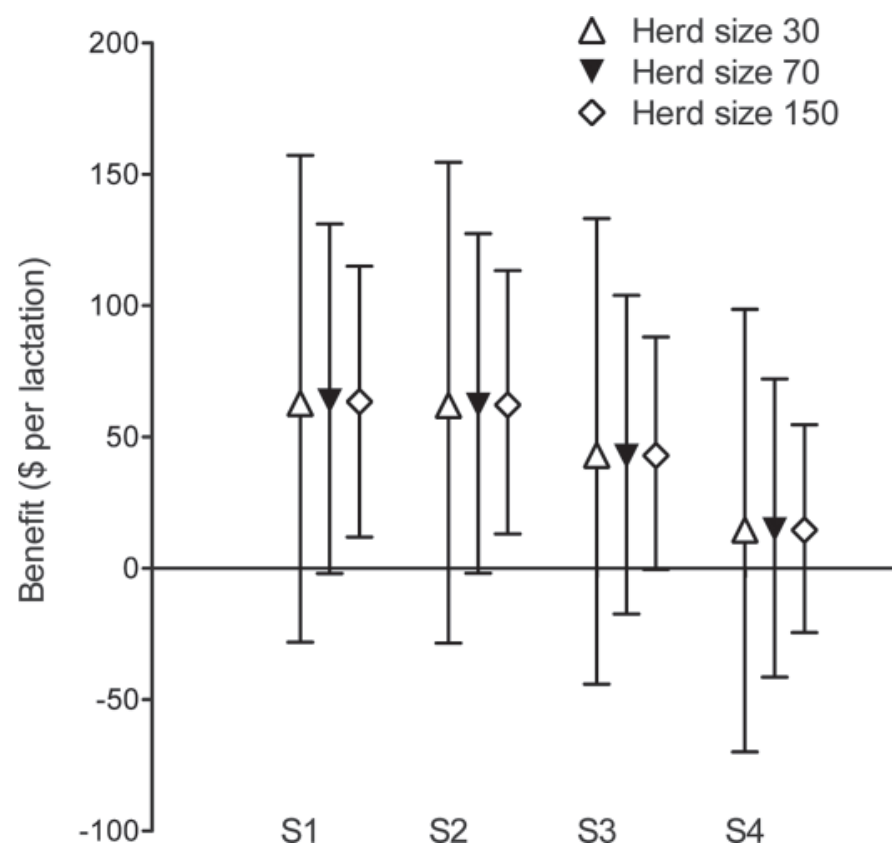

Figure 2. The effect of herd size on the model outcome. Strategy (S)1 = all cows are treated at calving without prior diagnosis; $\mathrm{S} 2=$ first-parity cows are all treated at calving, and second or higher parity cows are treated at calving if individual optical density ratio (ODR) $\geq 0.5$; S3 = first-parity cows are left untreated, and second or higher parity cows are treated at calving if individual $\mathrm{ODR} \geq 0.5 ; \mathrm{S} 4=$ all cows are treated at housing in fall without prior diagnosis. Conversion rate: $\mathrm{US} \$ 1=€ 0.7893$ at time of study. Error bars represent the $95 \%$ credible intervals.
The relationship between the herd's level of exposure to GI nematodes as assessed by bulk tank milk ELISA and the model outcome for the standard and low impact scenarios are given in Figure 3. In the standard scenario, the expected economic benefit for S1, S2, and $\mathrm{S} 3$ was greater than $\$ 0 /$ lactation from 0.3 ODR onward and for S4 from 0.6 ODR onward. In the low impact scenario, the expected economic benefit for $\mathrm{S} 1, \mathrm{~S} 2$, and $\mathrm{S} 3$ was greater than $\$ 0 /$ lactation from 0.7 ODR onward, but for S4, the expected economic benefit remained low at any level of exposure. From Figure 3, we concluded that when the objective is to maximize economic benefit, the selective treatment approach $\mathrm{S} 2$ has a small disadvantage over whole-herd treatment in herds with a high level of exposure (ODR $>0.8$ ), but that this disadvantage disappears in herds with medium and low levels of exposure.

\section{Sensitivity of Model to Changes in Economic Input Parameters}

The results of the sensitivity analyses to changes in economic input parameters are shown in Figure 4. The order of the 4 treatment strategies, when sorted by expected benefit, remained unchanged for any change in economic input parameters except when the cost of anthelmintics increased from $\$ 12.7$ to $\$ 15.2$ per dose or the cost to perform an ELISA was reduced from $\$ 8.9$ to $\$ 7.1 /$ test. In these cases, S1 and S2 had similar expected benefits. The model outcome was most influenced by changes in milk price for every treatment strategy. 

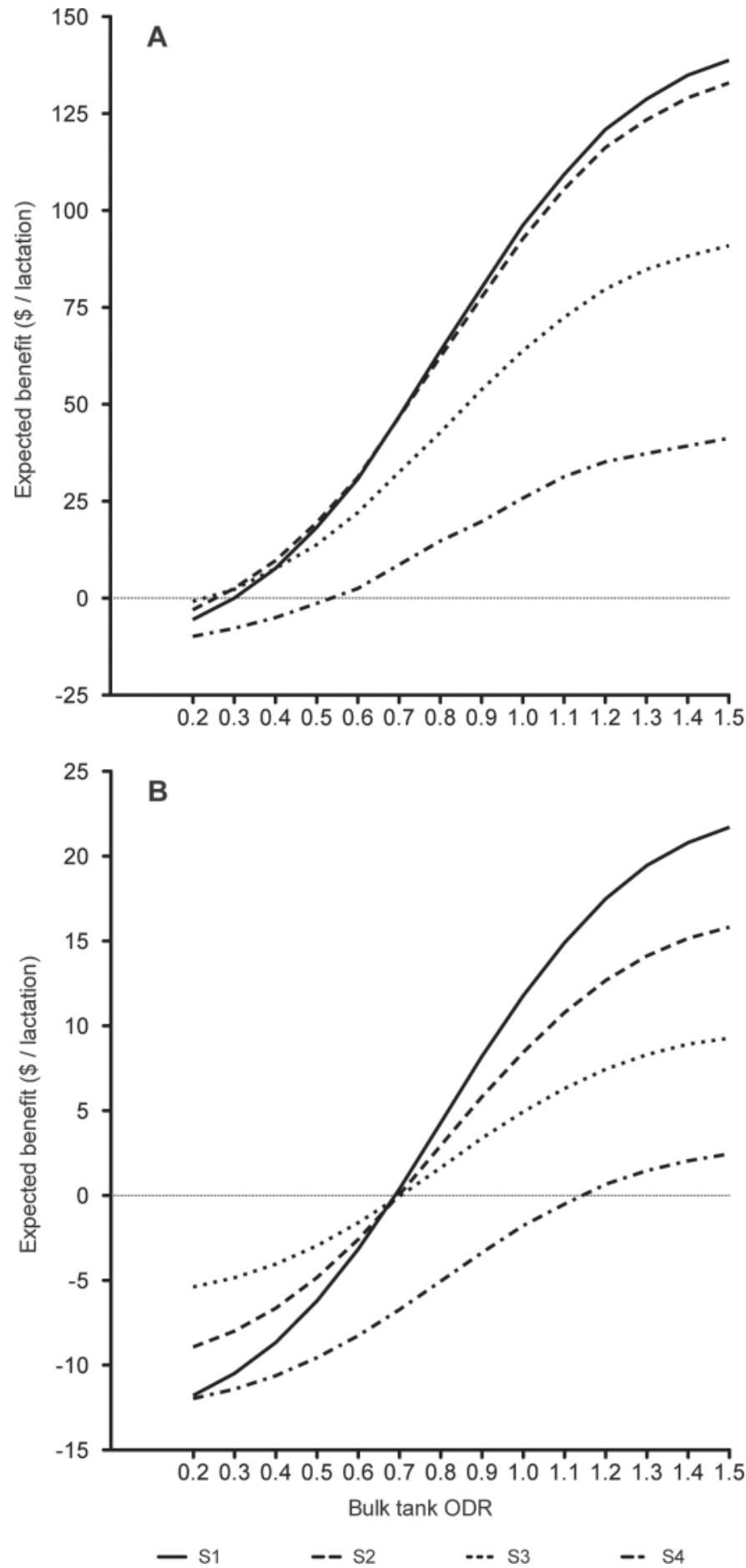

Figure 3. The relationship between the herd's level of exposure to gastrointestinal nematode infections as assessed by bulk tank milk ELISA and the expected benefit of an anthelmintic treatment strategy in the standard (A) and (B) low impact scenarios. Strategy (S)1 = all cows are treated at calving without prior diagnosis; $\mathrm{S} 2=$ first-parity cows are all treated at calving, and second or higher parity cows are treated at calving if individual optical density ratio $(\mathrm{ODR}) \geq 0.5 ; \mathrm{S} 3$ $=$ first-parity cows are left untreated, and second or higher parity cows are treated at calving if individual ODR $\geq 0.5$; $\mathrm{S} 4=$ all cows are treated at housing in fall without prior diagnosis. Conversion rate: US $\$ 1=€ 0.7893$ at time of study.
To a smaller extent, model outcome was also influenced by changes in the costs of anthelmintics, insemination, and diagnostics.

\section{DISCUSSION}

In the past, studies have focused on assessing the production effects of GI nematode infections in cattle (Sanchez et al., 2004). More recently, efforts have been conducted to assess the economic cost of these infections, albeit without considering to what extent these costs can be recovered by implementing control strategies (Charlier et al., 2012). Here, we present the first study on the economic effects of different intervention strategies at the herd level according to diagnostic thresholds.

The results indicated that efficient nematode control could result in an important return on investment with expected benefits for an average herd between $\$ 15$ and $\$ 63 /$ lactation, depending on the anthelmintic treatment strategy. In the low impact scenario, however, economic benefits were much lower and achieved only in herds with high levels of exposure. An important question is thus which production impact is realistic in a specific farm setting. The standard scenario used in our simulation represents the situation observed in 5 published trials on the effect of anthelmintic treatment responses on milk yield in Europe in the last decade (for a review, see Charlier et al., 2009a; Reist et al., 2011). The standard scenario may thus represent the situation on pasture-based farms in areas with generally high levels of infections such as northwestern Europe. No peerreviewed studies on the effect of anthelmintic treatment on fertility are available for Europe, so the estimates for effect of treatment on fertility were based on 2 other studies in Canada and Australia (Walsh et al., 1995; Sanchez et al., 2002b). The low impact scenario, on the other hand, was based on the results of a clinical trial in New Zealand (McPherson et al., 2001) and a recent clinical trial in Canada (Vanderstichel, 2011) and may represent the situation in areas in which cows are kept under permanent grazing conditions (New Zealand) or where the levels of infection and reliance on grazing for feed intake is generally low.

When the different strategies (S1 to S4) were compared, the most remarkable difference was that observed between strategies applying anthelmintic treatment at calving versus at housing. This difference can be explained by 3 factors. First, as observed by Charlier et al. (2010), we modeled a penalization by DIM for the effect of treatment on milk yield (the later the anthelmintic treatment is given during lactation, the lower the resulting milk yield response). Second, the length of the treatment effect was shorter when cows 
S1

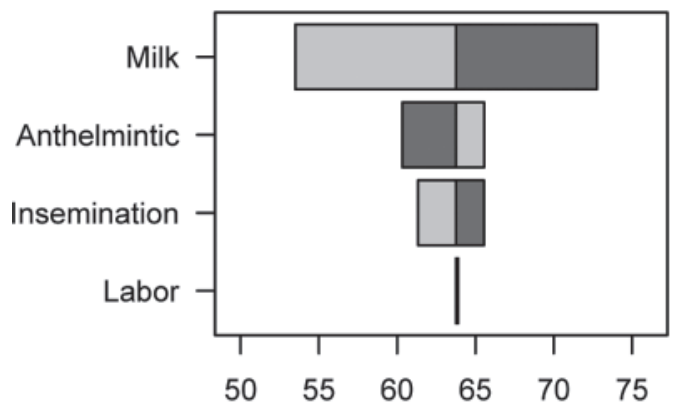

S3

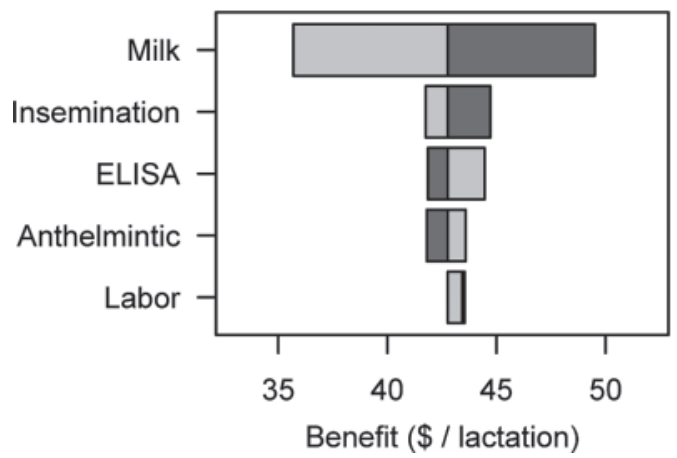

S2

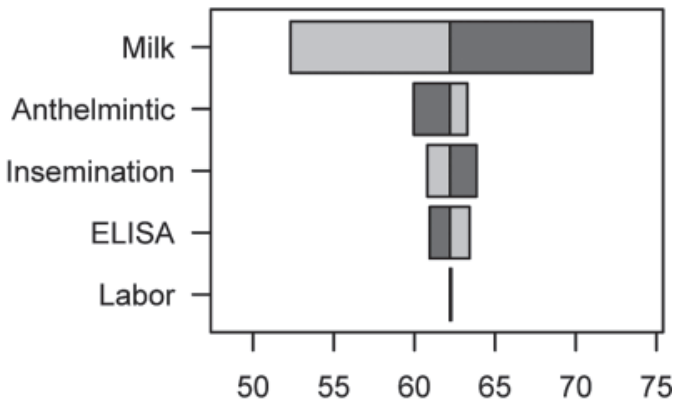

S4

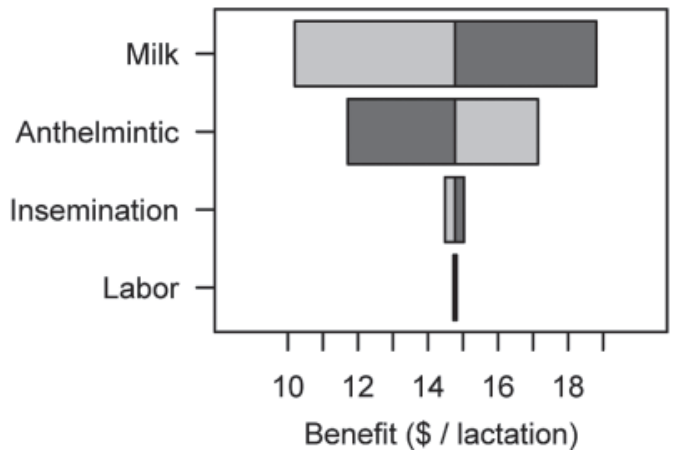

Figure 4. Sensitivity of the model outcome (expected benefit per lactation, $\$$ ) to changes in economic input parameters for the 4 evaluated treatment strategies. Strategy $(\mathrm{S}) 1=$ all cows are treated at calving without prior diagnosis; $\mathrm{S} 2=$ first-parity cows are all treated at calving, and second or higher parity cows are treated at calving if individual optical density ratio (ODR) $\geq 0.5$; S3 = first-parity cows are left untreated, and second or higher parity cows are treated at calving if individual ODR $\geq 0.5 ; \mathrm{S} 4=$ all cows are treated at housing in fall without prior diagnosis. Dark gray = effect when the value of input parameter is increased; light gray $=$ effect when the cost of the input parameter is decreased. Conversion rate: $\mathrm{US} \$ 1=€ 0.7893$ at time of study.

were treated at housing because it was assumed not to extend into the next lactation. Third, the effects of anthelmintic treatment on reproduction were assumed to occur only when treatment occurred within the first $75 \mathrm{~d}$ of lactation. Although more research is required to improve our knowledge on the relationships between timing of anthelmintic treatment and production responses, applying the current knowledge suggests that greater financial benefit will be achieved from strategies applying treatment at calving. In return, the economic benefits from treatment at housing will largely depend on the calving pattern of the herd, with the largest benefits being realized when most cows would calve around housing.

Within the strategies applying treatment at calving (S1 to S3), whole-herd treatment at calving (S1) generated a higher expected benefit than the selective treatment strategies (S2 and S3). However, the difference with S2 was small (\$1.56/lactation). Moreover, this difference disappeared in the sensitivity analysis when a higher input price for anthelmintics (\$15 instead of $\$ 13$ per dose) or a lower price to perform the diagnostics was used ( $\$ 7$ instead of $\$ 9$ per sample). This suggests that selective anthelmintic treatment strategies, using the currently available diagnostic to select the animals requiring treatment, can be economically competitive to whole-herd anthelmintic treatment strategies. The results (Figure 3A) indicate that, especially in herds with a low or average level of infection $(<0.8$ bulk tank ODR), a selective treatment approach (S2) will be equally or more economical than whole-herd treatment (S1). In the standard scenario, anthelmintic treatment resulted in expected benefits $>\$ 0$ per lactation when the bulk tank ODR $>0.3$. Applying selective treatment (S2) instead of whole-herd treatment in herds with a bulk tank ODR between 0.3 and 0.8 would reduce the amount of anthelmintics used in these herds by, on average, $52 \%$.

Huijps et al. (2009) showed that in addition to simple economic considerations, other aspects influence the final decision making of farmers, who often prefer easy-to-perform practices. In the present case, despite being economically competitive, selective treatment approaches would still involve more administrative (which 
animals to treat?) and labor effort. These drawbacks could be counterbalanced by integrating diagnostic test results and cost-benefit analysis in management software (Huijps et al., 2010; Steeneveld et al., 2011) to inform the farmer on the right time (e.g., around calving) to make an economic decision, while minimizing the required efforts.

The major considered advantage of applying a selective anthelmintic treatment regimen is the sustainability, with a lower selection pressure for anthelmintic resistance and fewer anthelmintic residues excreted in the environment (Jackson et al., 2009; Rombke et al., 2010). However, the effects of such selective treatment regimens on selection pressure for anthelmintic resistance are based on studies in small ruminants (Kenyon et al., 2009; Gaba et al., 2010), and no studies in cattle are available to date.

We observed large variation in the potential benefits for each treatment strategy, as indicated by the $95 \%$ credible intervals. Sensitivity analyses showed how these risks are influenced by herd size and the herd's level of infection with GI nematodes. The effect of herd size on $95 \%$ credible intervals was considerable, suggesting that this aspect should not be neglected when economic treatment decisions are taken. The herd's level of infection with GI nematodes as assessed by bulk tank milk ELISA not only influenced the risk associated with the different treatment strategies, but also had a large effect on the expected benefit. This highlights the value of bulk tank milk ELISA to make treatment decisions at the herd level. However, a potential weakness of the study is that we did not consider seasonal differences in individual ELISA results, which would have introduced an additional source of variation and could have led to a small bias in our study results.

The sensitivity analysis of the economic input parameters showed that milk price had the most important effect on the expected benefit from any treatment strategy. This is in agreement with the fact that benefit from increased milk production contributed $65 \%$, on average, to the total benefit of the anthelmintic treatment strategies and confirms the value of the current instinctive treatment approaches that are driven by milk prices. On the other hand, fertility responses also contributed a considerable part (35\%) of the benefit generated through anthelmintic therapy. Yet, until now, the effects of anthelmintic treatment on fertility of dairy cows remain poorly understood, with studies showing beneficial (Walsh et al., 1995; Sanchez et al., 2002b) or no effects (Sithole et al., 2006), and more research in this area could improve future economic assessments. Although the magnitude of the expected benefit was clearly affected by changes in economic input parameters, the order of the different treatment strategies when sorted by economic value was not. This indicates that the choice for the economic optimal treatment strategy is robust. The model we created was straightforward and intended to be able to give robust calculations for the decisions we wanted to study (anthelmintic treatments). This straightforwardness resulted in modeling solutions that did not always reflect reality. For instance, the effects of an increased calving interval are mostly due to a lower average milk production per cow per because of a delay for the next peak production. However, several cows will be culled and an increased calving interval for those cows will not have an effect because they are replaced by heifers at the start of lactation. These model simplifications in relation to reality are not expected to have a large effect on the final decisions.

Finally, in this study, we only investigated the effect of anthelmintic treatment because it is a straightforward management option that can be easily modeled and implemented. However, the association of several grazing management options with levels of nematode infection has recently been described (Charlier et al., 2005a; Bennema et al., 2010). In the future, the model could thus be extended by including such alternative or complementary control options.

\section{CONCLUSIONS}

The expected economic benefit and risk associated with anthelmintic treatment strategies on individual dairy farms depended largely on the herds' level of infection with GI nematodes, milk price, herd size, and lactation stage of the animals at the time of treatment. The results also indicate that more selective treatment strategies can compete economically with whole-herd treatment strategies and may be more sustainable because they are considered to slow the development of anthelmintic resistance and reduce the risk for residue deposition in the environment. Decision support systems that account for this multitude of factors are likely to improve future economic decisions on nematode control at the farm level. Future research in this area should focus on the effects of anthelmintic therapy on fertility responses and could extend the model by including control options through pasture management.

\section{ACKNOWLEDGMENTS}

We acknowledge Andy Forbes (Merial, Lyon, France) and Miel Hostens (UGent, Ghent, Belgium) and several Belgian dairy farmers for their useful comments and expert opinion during the construction of the model. The 
research of J. Charlier was supported by the Agency for Innovation by Science and Technology of Flanders (IWT Vlaanderen, project OZM090697); B. Levecke was funded by the Fund for Scientific Research-Flanders (Belgium) (F.W.O.-Vlaanderen). The project was cofinanced by the E.U. FP7 GLOWORM project (grant agreement no 288975CP-TP-KBBE.2011.1.3-04).

\section{REFERENCES}

Bennema, S., J. Vercruysse, E. Claerebout, T. Schnieder, C. Strube, E Ducheyne, G. Hendrickx, and J. Charlier. 2009. The use of bulktank milk ELISAs to study the spatial distribution of Fasciola hepatica, Ostertagia ostertagi and Dictyocaulus viviparus in Flanders (Belgium). Vet. Parasitol. 165:51-57.

Bennema, S. C., J. Vercruysse, E. Morgan, K. Stafford, J. Höglund, J. Demeler, G. von Samson-Himmelstjerna, and J. Charlier. 2010. Epidemiology and risk factors for exposure to gastrointestinal nematodes in dairy herds in northwestern Europe. Vet. Parasitol. 173:247-254.

Charlier, J., P. Camuset, E. Claerebout, B. Courtay, and J. Vercruysse. 2007a. A longitudinal survey of anti-Ostertagia ostertagi antibody levels in individual and bulk tank milk in two dairy herds in Normandy. Res. Vet. Sci. 83:194-197.

Charlier, J., E. Claerebout, E. De Mûelenaere, and J. Vercruysse. 2005a. Associations between dairy herd management factors and bulk tank milk antibody levels against Ostertagia ostertagi. Vet. Parasitol. 133:91-100.

Charlier, J., L. Duchateau, E. Claerebout, and J. Vercruysse. 2005b. Assessment of the repeatability of a milk Ostertagia ostertagi ELISA and effects of sample preparation. Prev. Vet. Med. 68:277-288.

Charlier, J., L. Duchateau, E. Claerebout, and J. Vercruysse. 2007b. Predicting milk-production responses after an autumn treatment of pastured dairy herds with eprinomectin. Vet. Parasitol. 143:322-328

Charlier, J., J. Höglund, G. von Samson-Himmelstjerna, P. Dorny, and J. Vercruysse. 2009a. Gastrointestinal nematode infections in adult dairy cattle: Impact on production, diagnosis and control. Vet. Parasitol. 164:70-79.

Charlier, J., J. Troeng, J. Höglund, J. Demeler, K. Stafford, G. Coles, G. von Samson-Himmelstjerna, M. Merza, and J. Vercruysse. 2009b. Assessment of the within- and between-laboratory repeatability of a commercially available Ostertagia ostertagi milk ELISA. Vet. Parasitol. 164:66-69.

Charlier, J., M. Van der Voort, H. Hogeveen, and J. Vercruysse. 2012. ParaCalc ${ }^{\boxplus}$ - A novel tool to estimate the costs of worm infections on the dairy herd. Vet. Parasitol. 184:204-211.

Charlier, J., J. Vercruysse, J. Smith, R. Vanderstichel, H. Stryhn, E. Claerebout, and I. Dohoo. 2010. Evaluation of anti-Ostertagia ostertagi antibodies in individual milk samples as decision parameter for selective anthelmintic treatment in dairy cows. Prev. Vet. Med. 93:147-152.

CRV. 2010. Jaarstatistieken Vlaanderen 2009. Accessed Jul. 1, 2011. www.vrv.be.

CRV. 2011. Sire catalogue. Accessed Jul. 1, 2011. https://www.vrv.be/ $\mathrm{nl} /$ stierenkaart/index.htm.

Forbes, A. B., C. A. Huckle, and M. J. Gibb. 2004. Impact of eprinomectin on grazing behaviour and performance in dairy cattle with sub-clinical gastrointestinal nematode infections under continuous stocking management. Vet. Parasitol. 125:353-364.

Gaba, S., J. Cabaret, C. Sauve, J. Cortet, and A. Silvestre. 2010. Experimental and modelling approaches to evaluate different aspects of the efficacy of targeted selective treatment of anthelmintics against sheep parasite nematodes. Vet. Parasitol. 171:254-262.

Gibb, M. J., C. A. Huckle, and A. B. Forbes. 2005. Effects of sequential treatments with eprinomectin on performance and grazing behaviour in dairy cattle under daily-paddock stocking management. Vet. Parasitol. 133:79-90.
Gross, S. J., W. G. Ryan, and H. W. Ploeger. 1999. Anthelmintic treatment of dairy cows and its effect on milk production. Vet. Rec. 144:581-587.

Guitián, F. J., I. R. Dohoo, R. J. F. Markham, G. Conboy, and G. P. Keefe. 1999. Relationships between bulk-tank antibodies to Ostertagia ostertagi and herd-management practices and measures of milk production in Nova Scotia dairy herds. Prev. Vet. Med. 47:79-89.

Huijps, K., H. Hogeveen, T. J. G. M. Lam, and R. B. M. Huirne. 2009 Preference of cost factors for mastitis management among Dutch dairy farmers using adaptive conjoint analysis. Prev. Vet. Med. 92:351-359.

Huijps, K., H. Hogeveen, T. J. G. M. Lam, and A. G. J. M. Oude Lansink. 2010. Costs and efficacy of management measures to improve udder health on Dutch dairy farms. J. Dairy Sci. 93:115-124.

Inchaisri, C., R. Jorritsma, J. C. M. Vernooij, P. L. A. M. Vos, G. C. van der Weijden, and H. Hogeveen. 2011. Cow effects and estimation of success of first and following inseminations in Dutch dairy cows. Reprod. Domest. Anim. 46:1043-1049.

Inchaisri, C., R. Jorritsma, P. L. A. M. Vos, G. C. van der Weijden, and H. Hogeveen. 2010. Economic consequences of reproductive performance in dairy cattle. Theriogenology 74:835-846.

Jackson, F., D. Bartley, Y. Bartley, and F. Kenyon. 2009. Worm control in sheep in the future. Small Rumin. Res. 86:40-45.

Kenyon, F., A. W. Greer, G. C. Coles, G. Cringoli, E. Papadopoulos, J. Cabaret, B. Berrag, M. Varady, J. A. Van Wyk, E. Thomas, J. Vercruysse, and F. Jackson. 2009. The role of targeted selective treatments in the development of refugia-based approaches to the control of gastrointestinal nematodes in small ruminants. Vet. Parasitol. 164:3-11.

Love, D. C., M. F. Davis, A. Bassett, A. Gunther, and K. E. Nachman 2011. Dose imprecision and resistance: Free-choice medicated feeds in industrial food animal production in the United States. Environ. Health Perspect. 119:279-283.

Lumaret, J. P., and F. Errouissi. 2002. Use of anthelmintics in herbivores and evaluation of risks for the non target fauna of pastures. Vet. Res. 33:547-562.

McPherson, W. B., R. P. Gogolewski, B. Slacek, A. S. Familton, S. J Gross, A. E. Maciel, and W. G. Ryan. 2001. Effect of a peri-parturient eprinomectin treatment of dairy cows on milk production. N. Z. Vet. J. 49:106-110.

Nødtvedt, A., I. Dohoo, J. Sanchez, G. Conboy, L. DesCôteaux, and G. Keefe. 2002. Increase in milk yield following eprinomectin treatment at calving in pastured dairy cattle. Vet. Parasitol. 105:191206.

R Development Core Team. 2010. R: A language and environment for statistical computing. R Foundation for Statistical Computing, Vienna, Austria. http://www.R-project.org/.

Reist, M., A. B. Forbes, M. Bonfanti, W. Beretta, and K. Pfister. 2011 Effect of eprinomectin treatment on milk yield and quality in dairy cows in South Tyrol, Italy. Vet. Rec. 168:484.

Reist, M., T. D. Medjitna, U. Braun, and K. Pfister. 2002. Effect of a treatment with eprinomectin or trichlorfon on the yield and quality of milk produced by multiparous dairy cows. Vet. Rec. 151:377-380.

Rombke, J., A. Coors, A. A. Fernandez, B. Forster, C. Fernandez, J. Jensen, J. P. Lumaret, M. A. P. Cots, and M. Liebig. 2010. Effects of the parasiticide ivermectin on the structure and function of dung and soil invertebrate communities in the field (Madrid, Spain). Appl. Soil Ecol. 45:284-292.

Sanchez, J., I. Dohoo, J. Carrier, L. Des, and L. Coteaux. 2004. A meta-analysis of the milk-production response after anthelmintic treatment in naturally infected adult dairy cows. Prev. Vet. Med. 63:237-256.

Sanchez, J., I. Dohoo, K. Leslie, G. Keefe, F. Markham, and F. Sithole 2005. The use of an indirect Ostertagia ostertagi ELISA to predict milk production response after anthelmintic treatment in confined and semi-confined dairy herds. Vet. Parasitol. 130:115-124.

Sanchez, J., I. Dohoo, A. Nødtvedt, G. Keefe, F. Markham, K. Leslie, L. DesCôteaux, and J. Campbell. 2002a. A longitudinal study of gastrointestinal parasites in Canadian dairy farms. The value of 
an indirect Ostertagia ostertagi ELISA as a monitoring tool. Vet. Parasitol. 107:209-226.

Sanchez, J., A. Nødtvedt, I. Dohoo, and L. DesCoteaux. 2002b. The effect of eprinomectin treatment at calving on reproduction parameters in adult dairy cows in Canada. Prev. Vet. Med. 56:165-177.

Sithole, F., I. Dohoo, K. Leslie, L. DesCoteaux, S. Godden, J. Campbell, G. Keefe, and J. Sanchez. 2006. Effect of eprinomectin pour-on treatment around calving on reproduction parameters in adult dairy cows with limited outdoor exposure. Prev. Vet. Med. $75: 267-279$.

Steeneveld, W., T. van Werven, H. W. Barkema, and H. Hogeveen. 2011. Cow-specific treatment of clinical mastitis: An economic approach. J. Dairy Sci. 94:174-188.

Sutherland, I. A., and D. M. Leathwick. 2011. Anthelmintic resistance in nematode parasites of cattle: A global issue? Trends Parasitol. $27: 176-181$.
Vanderstichel, R. 2011. Development of guidelines for immunological monitoring of gastrointestinal parasites in dairy cattle. $\mathrm{PhD}$ Thesis. University of Prince Edward Island, Charlottetown, PEI, Canada.

Walsh, A., P. J. Younis, and J. M. Morton. 1995. The effect of ivermectin treatment of late pregnant dairy cows in south-west Victoria on subsequent milk production and reproductive performance. Aust. Vet. J. 72:201-207.

Webster, R., K. Knox, F. Berger, J. Delaveau, and A. B. Forbes. 2008 Comparison of the time required to administer three different fluke and worm combination products to commercial beef cattle at housing. Vet. Ther. 9:45-52. 